\title{
Effect of a multi-dimensional case management model on anti-retroviral therapy-related outcomes among people living with human immunodeficiency virus in Beijing, China
}

Lili Dai ${ }^{1}$, Xiaochun Yu², Ying Shao', Yali Wang ${ }^{1}$, Zaicun Li', Jiangzhu Ye ${ }^{1}$, Shaoli Bai ${ }^{3}$, Xiaoling Guo ${ }^{3}$, Jianyun Wang ${ }^{3}$, Bin Su', Taiyi Jiang ${ }^{1}$, Tong Zhang ${ }^{1}$, Hao Wu' ${ }^{1}$ Sarah Robbins Scott ${ }^{4}$, An Liu $^{1 *}$ and Lijun Sun ${ }^{1 *}$

\begin{abstract}
Background: This paper introduces a comprehensive case management model uniting doctors, nurses, and nongovernmental organizations (NGOs) in order to shorten the time from HIV diagnosis to initiation of antiviral therapy, improve patients' adherence, and ameliorate antiretroviral treatment (ART)-related outcomes.

Methods: All newly diagnosed human immunodeficiency virus (HIV) cases at Beijing YouAn Hospital from January 2012 to December 2013 were selected as the control group, while all newly diagnosed HIV-infected patients from January 2015 to December 2016 were selected as the intervention group, receiving the comprehensive case management model.
\end{abstract}

Results: 4906 patients were enrolled, of which 1549 were in the control group and 3357 in the intervention group. The median time from confirming HIV infection to ART initiation in the intervention group was 35 (18-133) days, much shorter than the control group (56 (26-253) days, $P<0.001)$. Participants in the intervention group had better ART adherence compared to those in the control group (intervention: 95.3\%; control: 89.2\%; $p<0.001$ ). During the 2 years' follow-up, those receiving case management were at decreased odds of experiencing virological failure (OR: $0.27,95 \% \mathrm{Cl}: 0.17-0.42, P<0.001)$. Observed mortality was 0.4 deaths per 100 patient-years of follow-up for patients in the control group compared with 0.2 deaths per 100 patient-years of follow-up in the intervention group.

Conclusions: People living with HIV engaged in the comprehensive case management model were more likely to initiate ART sooner and maintained better treatment compliance and improved clinical outcomes compared to those who received routine care. A comprehensive case management program could be implemented in hospitals across China in order to reduce the HIV disease burden in the country.

Keywords: Case management, HIV, Virologic failure, Retention rate

\footnotetext{
*Correspondence: liuan75@163.com; sunlijunkity@163.com

${ }^{1}$ Center for Infectious Diseases, Beijing Youan Hospital, Capital Medical University, Beijing 100069, China

Full list of author information is available at the end of the article
}

(c) The Author(s). 2020 Open Access This article is licensed under a Creative Commons Attribution 4.0 International License, which permits use, sharing, adaptation, distribution and reproduction in any medium or format, as long as you give appropriate credit to the original author(s) and the source, provide a link to the Creative Commons licence, and indicate if changes were made. The images or other third party material in this article are included in the article's Creative Commons licence, unless indicated otherwise in a credit line to the material. If material is not included in the article's Creative Commons licence and your intended use is not permitted by statutory regulation or exceeds the permitted use, you will need to obtain permission directly from the copyright holder. To view a copy of this licence, visit http://creativecommons.org/licenses/by/4.0/ The Creative Commons Public Domain Dedication waiver (http://creativecommons.org/publicdomain/zero/1.0/) applies to the data made available in this article, unless otherwise stated in a credit line to the data. 


\section{Background}

Human immunodeficiency virus (HIV) and acquired immune deficiency syndrome (AIDS) continue to be global health threats. According to the Joint United Nations Programme on HIV/AIDS (UNAIDS), 37.9 million people were living with HIV (PLWH), 1.7 million people were newly infected with HIV, and 770,000 people died from AIDS related illness in 2018 [1]. This is reflective of China's epidemic as well, where new cases continue to be identified. The latest AIDS epidemic report estimated approximately 1.25 million PLWH in China by the end of 2018, with almost 80,000 new infections occurring every year [2]. the disease impacts almost more than one million people and is a serious public health and social problem [3].

The advent of antiretroviral treatment (ART) remains the most effective way to treat HIV and reduce transmission $[4,5]$. In China, all people living with HIV are provided free ART therapy through the "Four Frees and One Care" program, which began in 2003. Initially, this program provided free ART mainly focus on PLWH whom had CD4 cell counts less than $200 / \mu$ in 2004, however, this changed to less than $350 / \mu \mathrm{l}$ in 2008 and less than $500 / \mu \mathrm{l}$ in 2014. Patients with higher CD4 cell counts were treated with ART when they made a special request to the providers [6]. However, currently, because of the undisputed benefits of ART, international guidelines recommend antiretroviral therapy for all patients with HIV infection regardless of CD4 cell count, and therefore our center has adaopted these guidelines [7-10]. Furthermore, the initiation of treatment as soon as possible after confirmation of HIV infection, known as "Rapid ART," has been supported by various international groups, including the World Health Organization (WHO) [11]. Under current conditions of an absence of a vaccine or cure, "Rapid ART" can help control the HIV epidemic $[12,13]$.

However, the current standard-of-care pathway from initial HIV screening to starting ART in China is convoluted, involving multiple hospital visits and separate blood draws [14, 15]. In addition, most of the new diagnosed patients are reluctant to go to immunodeficiency clinics seeking ART, as they are asymptomatic. It was reported that it usually takes months before a new diagnosed patient starts treatment [16-19], and several patients lost during this period. Furthermore, with the increasing number of newly infected patients, and with the wide spread availability of free ART, and the associated benefit of prolonged survival time for the patients, more and more people are opting to receiving ART in China [12, 20]. Inspite of free ART, the HIV associated disease burden remains and continues to strain the existing healthcare system. Thus, innovative and effective HIV case management models are urgently needed in China [14, 16, 17].
Case management has been advocated as a strategy to meet the need for supportive services, to improve utilization of ambulatory services, and prevent/decrease unsatisfactory clinical outcomes for people infected with HIV [21]. The literature is scant however, on the impact of a comprehensive case management models on the time to ART initiation as it relates to ART-related outcomes in China. We report the establishment of a comprehensive case management model for HIV care that includes a coordinated efforts among doctors, nurses, and local non-governmental organizations (NGOs) and evaluated its impact on early ART and ART-related outcomes, including retention in care, virologic failure, and mortality.

\section{Methods}

\section{Study population}

This was an observational study of confirmed HIVpositive patients attending Beijing Youan Hospital, Capital Medical University, in Beijing, China from 2012 to 2016. Beijing Youan Hospital is one of the largest infectious disease hospitals in China, where more than half of all PLWH in Beijing receive care and ART services. HIV-positive patients attending Youan Hospital from January 2012 to December 2013 (prior to the implementation of the case management model) were selected as the control group, while all newly diagnosed HIVinfected patients from January 2015 to December 2016 (after the case management model was implemented) were selected as the intervention group.

Patients were eligible for the study if they met the following inclusion criteria: 1) received a positive HIV-1 test, 2) $\geq 18$ years old, 3) attending Youan Hospital for HIV-related care, and 4) initiated treatment either during 2012-2013 or 2015-2016. Patient data, including demographic data, date of HIV diagnosis, date of ART initiation, and ART adherence were downloaded from the HIV/AIDS comprehensive response information management system (CRIMS), managed by Youan Hospital. Patients who had been previously treated, pregnant, not eligible for free ART, had opportunistic infections, and patients with incomplete data, such as a lack of baseline CD4 cell counts, HIV diagnosis date, or date of ART initiation, were excluded. This study was approved by the Beijing Youan Hospital Research Ethics Committee (No. 2019-057).

\section{Study design}

All participants in the study received free ART according to the guidelines of the national "Four Frees and One Care" program. The control group received routine-HIV care from Youan hospital, including ART guidance, psychological support, health education, and laboratory follow-up. Those in the intervention group received the 
extended "doctor/nurse/NGO" case management model during the first 3 months of their care. This "doctor/ nurse/NGO" case management model is a clientcentered, strengths-based model aimed at meeting the medical and social needs of HIV-infected individuals. In this model, based on routine follow-up care, a handful of activities were conducted. First, with the help of NGOs, healthcare workers gave lectures every 2 weeks for people who had high risk of HIV infection in order to raise their awareness of the benefits of early treatment. Second, NGOs, in cooperation with medical workers, provided additional outreach on ART adherence. Members from these organizations also helped patients who had just been diagnosed with HIV finish the necessary blood tests needed before initiating ART and accompanied them to the hospital. Third, if a participant screened positive for HIV, a case manager would hold a patient assessment in a private room, providing psychological support, discussing the benefits of early ART treatment. If a participant was confirmed positive for HIV, the case manager met with the participant again in private, informing the participant of his/her status and offering support, helping them acquire more homecare. The case manager and volunteer from the NGO contacted the patients every 2 days within the first week of the intervention, and then every week for the remainder of the first month, followed by every 2 weeks for the next 2 months, by WeChat. They discuss any patient needs or discomforts and encourage them to take their medication on time.

All necessary data, including demographic characteristics (age, gender, education level, route of HIV transmission), treatment status, initial ART regimens, and follow-up status, were collected from the Beijing Youan Hospital HIV/AIDS antiviral treatment system. The ART rate, pre-treatment interval, adherence, virologic failure, retention rate, and mortality rate were compared between the intervention and control groups after 2 years of follow-up.

ART rate was calculated as the number of patients initiating ART divided by number of new patients diagnosed. Adherence to ART was a self-reported measure combined with nurses counting pills, defined as the number of times a participant reported missing a dose in the last month. Adherence to ART of every follow-up was based on the doses the patient had taken divided by expected number of in the last 30 days prior to the interview. The total adherence was measured by average all the adherence percentage of every follow-up. Participants with $\geq 95 \%$ adherence were classified as having "good adherence" while those that took below 95\% of their ART were classified as having poor adherence [22].

The pre-treatment interval was the time between confirmation of HIV and initiation of ART treatment which was defined as the number of days from when a participant tested positive for HIV using a Western Blot test to when he/she initiated treatment. Virologic failure was defined as two consecutive plasma HIV ribonucleic acid (RNA) tests of $>200$ copies/ml after 24 weeks of receiving ART [23]. Based on the National Free AIDS Antiretroviral Therapy program, follow-up status for adults on ART is divided into five categories: on treatment, loss to follow-up, death, transfer to other treatment centers, and withdrawal [23]. In this study, died, loss to followup, and withdrawal were all defined as stopping followup. Retention rate was calculated as the number of patients still on treatment divided by the number of patients whom initiated ART.

All participants were followed at 2 weeks, 1 month, 2 months, 3 months, and each 3 -month period until 2 years after anti-viral treatment initiation. ART adherence, routine blood work, and other tests were conducted according to Chinese clinical guidelines at each follow-up.

\section{Statistical analysis}

Baseline and follow-up data were downloaded from CRIMS for analysis. Continuous variables were described using median and inter-quartile ranges (IQR), while categorical variables were described by percentages. The Chi-square test was used for categorical variables and the Mann-Whitney test was used for continuous variables. The cumulative probability of ART retention was calculated every 3 months after starting ART by life table analysis. A multiple logistic regression model and linear regression model were built to explore the effect of using the YouAan hospital management model on virologic failure and the pre-treatment interval, respectively. The predictors included in the multivariate model were selected based on a significance level of $P<0.1$ in the univariate analyses or other factors that may have an impact on the failure of antiretroviral treatment. A Kaplan-Meier plot was used to assess the effect of case management on long-term survival among patients.

\section{Results}

\section{Baseline characteristics of study participants}

1825 patients were newly diagnosed with HIV from January 2012 through December 2013 and 3697 patients were diagnosed with HIV from January 2015to December 2016. 276 and 340 patients were excluded from the two groups, respectively, for a total of 4906 patients enrolled in the study. 1549 patients who initiated ART from January 2012 to December 2013 were selected as the control group, while 3357 patients who initiated ART from January 2015 to December 2016 were selected as the intervention group (Fig. 1). Of all participants, the median age was 35 years, the majority (96.1\%), were 


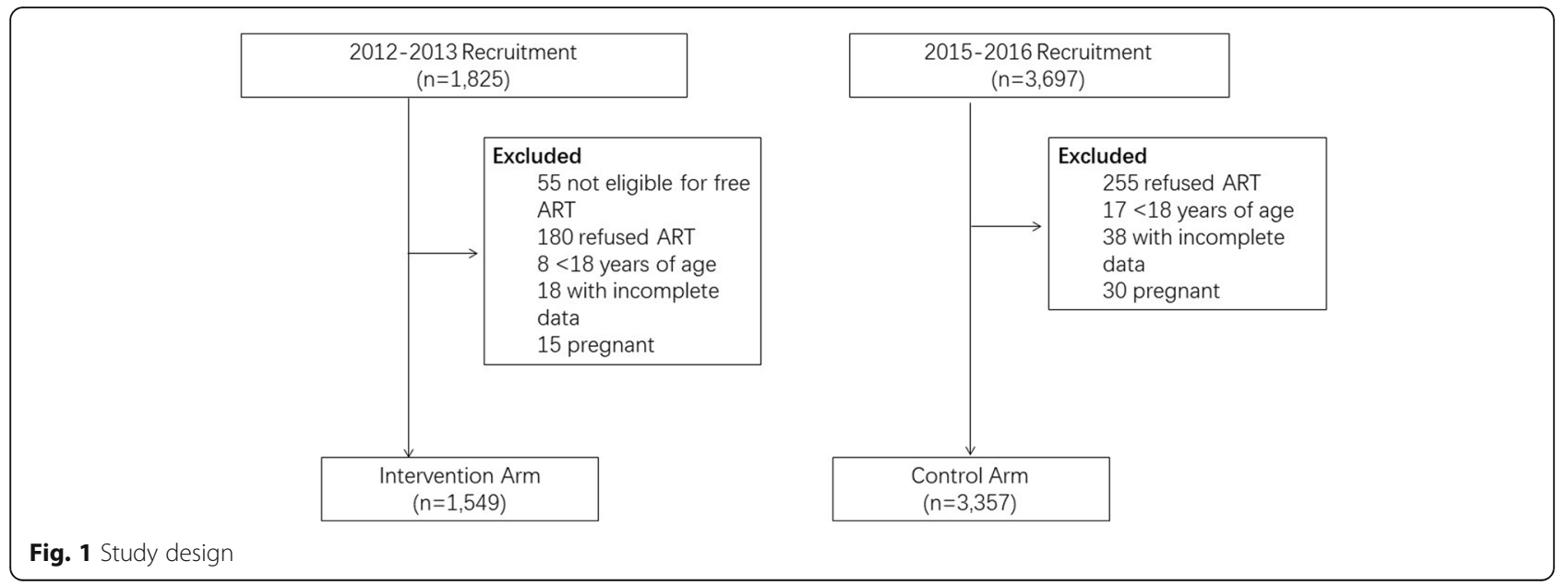

male, $69.3 \%$ were married, and $87.4 \%$ reported a homosexual route of infection (Table 1). There were $89 \%$ patients were categorized with Stage I or II clinical infection, and approximately $62 \%$ of patients had an average CD4 cell count of under 350/ $\mu \mathrm{l}$. Age, gender, marital status, route of HIV transmission, WHO clinical stage, viral loads and baseline CD4 cell count were statistically significantly different $(p<0.001)$ between the control and intervention groups. Patients in the intervention group were younger and had higher CD4 cell counts. Additionally, more participants in the intervention group were married and reported a homosexual route of HIV transmission.

\section{Impact of case management on ART-related outcomes}

The ART rate was $89.8 \%(1590 / 1770)$ and $93.1 \%$ (3442/ 3697) in control and intervention group, respectively $(P<0.001)$. The median pre-treatment interval in the intervention group was 35 (18-133) days, statistically significantly shorter than in the control group $(P<0.001)$, which was $56(26-253)$ days (Table 2$)$. More participants in the intervention group had good ART adherence compared to those in the control group (intervention: 95.3\%; control: 89.2\%; $P<0.001$ ), while more control participants experienced virological failure (intervention: $0.9 \%$; control: $3.9 \%, p<0.001$ ). Observed mortality was 0.7 deaths of follow-up for patients in the control group compared with 0.3 deaths in the intervention group $(P<0.001)$. Similar results were obtained among patients with CD4 cells less than350/ $\mu \mathrm{l}$ (Table 2).

\section{Factors associated with virologic failure}

The results of the multivariate logistic regression are summarized in Table 3. Participants who received case management were at decreased odds of virological failure (OR: $0.27,95 \%$ CI: $0.17-0.42, p<0.001)$. Additionally, participants with more severe disease, specifically
WHO stage III or stage IV were at increased odds of virological failure (OR: 1.94, 95\% CI: 1.17-3.21, $p<0.01$ (Table 3).

\section{Factors associated with the pre-treatment interval}

As shown in Table 4, the days from HIV diagnosis to ART initiation was only associated with the implementation of the comprehensive case-management, and it was negatively correlated with the days between HIV diagnosis and ART initiation.

\section{Mortality}

A total of $21(0.4 \%)$ patients died during the 2 years' study period (Fig. 2). There were 0.7 deaths for patients who did not receive case management (control group) compared with 0.3 deaths for those who received case management (intervention group). The Kaplan-Meier survival analysis summarizes the survival curve between the two groups, indicating that the control group had a higher cumulative incidence of mortality compared to the intervention group $(P=0.023)$.

\section{Discussion}

Case management uses a client-centered, multi-faceted approach to ensure health and psychological support for people living with HIV. While research has shown the benefits of implementing case management on HIVrelated outcomes, little has been done in China to assess the impact of comprehensive interventions on early ART and patient-related outcomes together. In this study, we evaluated the impact of one such strategy at Beijing Youan Hospital, one of China's largest clinics treating more than 9000 HIV infected individuals. In this study, we found that after implementation of a comprehensive case-management program, ART-related outcomes including retention and survival increased, while the time from initial HIV diagnosis to initiation of treatment was shortened. This study provides evidence to support a 
Table 1 Demographic characteristics of the study participants at baseline

\begin{tabular}{|c|c|c|c|c|}
\hline Variable & Total $(n=4906)$ & Control group $(n=1549)$ & Intervention group $(n=3357)$ & $P$-value \\
\hline Age (Median, IQR) & $35(30-43)$ & $37(32-46)$ & $33(29-40)$ & $<0.001$ \\
\hline$<30$ & $1181(24.1)$ & $165(10.7)$ & $1016(30.3)$ & \\
\hline $30-49$ & $3100(63.2)$ & 1136 (73.3) & $1964(58.5)$ & \\
\hline $50+$ & $625(12.7)$ & $248(16.0)$ & $377(11.2)$ & \\
\hline Gender & & & & $<0.001$ \\
\hline Male & $4716(96.1)$ & $1467(94.7)$ & $3249(96.8)$ & \\
\hline Female & $190(8.3)$ & $82(5.3)$ & $108(3.2)$ & \\
\hline Marital status & & & & $<0.001$ \\
\hline Married & $3400(69.3)$ & $937(60.5)$ & $2463(73.4)$ & \\
\hline Cohabitating & $1279(26.1)$ & $525(33.9)$ & $754(22.5)$ & \\
\hline Single & $203(4.1)$ & $77(5.0)$ & $126(3.8)$ & \\
\hline Separated/divorced & $24(0.5)$ & $10(0.6)$ & $14(0.4)$ & \\
\hline Route of transmission & & & & $<0.001$ \\
\hline Blood transfusion & $75(1.5)$ & $23(1.5)$ & $52(1.5)$ & \\
\hline Homosexual & 4289 (87.4) & $1282(82.8)$ & 3007 (89.6) & \\
\hline Heterosexual & $329(6.7)$ & $152(9.8)$ & $177(5.3)$ & \\
\hline Mother to child/other & $213(4.3)$ & $92(5.9)$ & $121(3.6)$ & \\
\hline WHO Clinical stage ${ }^{2}$ & & & & $<0.001$ \\
\hline Stage I and Stage || & $4368(89.0)$ & $1292(83.4)$ & 3076 (91.6) & \\
\hline Stage III and Stage IV & $538(11.0)$ & $192(16.6)$ & $281(8.4)$ & \\
\hline $\begin{array}{l}\text { CD4 cell counts } \\
\text { (Median, IQR) }\end{array}$ & $300(191-416)$ & $264(163-351)$ & $322(207-442)$ & $<0.001$ \\
\hline$<500$ & $4229(86.2)$ & $1432(92.5)$ & 2797 (83.3) & \\
\hline $500+$ & $677(13.8)$ & $117(7.5)$ & $560(16.7)$ & \\
\hline Viral loads ${ }^{3}($ Mean \pm SD $)$ & $4.2 \pm 0.83$ & $4.2 \pm 0.73$ & $4.2 \pm 0.86$ & 0.030 \\
\hline ART Regimen & & & & 0.530 \\
\hline $\mathrm{EFV} / \mathrm{LPV} / \mathrm{r}+3 \mathrm{TC}+\mathrm{AZT} / \mathrm{TDF}$ & $4777(97.4)$ & $1505(97.2)$ & 3066 (97.5) & \\
\hline Other & $129(2.6)$ & $44(2.8)$ & $85(2.5)$ & \\
\hline
\end{tabular}

IQR interquartile range; WHO World Health Organization, ART anti-retroviral therapy; EFV Efavirenz; 3TC Lamivudine; AZT Zidovudine; TDF Tenofovir; LPV/r Kaletra 2 WHO Clinical Stage: a way to categorize HIV disease severity based on new or recurrent clinical events. There are 4 WHO clinical stages which range from mild symptoms (WHO clinical stage 1) to severe symptoms (WHO clinical stage 4)

3915 did not have baseline viral loads

Table 2 Antiviral therapy related outcomes of the participants, by study arm

\begin{tabular}{|c|c|c|c|c|c|c|}
\hline \multirow[t]{2}{*}{ Indicator } & \multicolumn{3}{|l|}{ All Participants } & \multicolumn{3}{|c|}{ 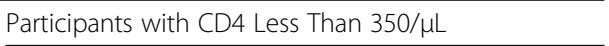 } \\
\hline & $\begin{array}{l}\text { Control group } \\
(n=1549)\end{array}$ & $\begin{array}{l}\text { Intervention group } \\
(n=3357)\end{array}$ & $P$-value & $\begin{array}{l}\text { Control group } \\
(n=1158)\end{array}$ & $\begin{array}{l}\text { Intervention group } \\
(n=1983)\end{array}$ & $P$-value \\
\hline Virological failure & $60(3.9)$ & $31(0.9)$ & $<0.001$ & $51(4.4)$ & $27(1.4)$ & $<0.001$ \\
\hline Retention in care & $1466(94.6)$ & $3159(94.1)$ & 0.449 & $1096(94.6)$ & $1774(93.7)$ & 0.290 \\
\hline pre-treatment interval (days) ${ }^{1}$ & $56(26-253)$ & $35(18-133)$ & $<0.001$ & $48(25-252)$ & $35(17-106)$ & $<0.001$ \\
\hline Good ART adherence & $1381(89.2)$ & 3199 (95.3) & $<0.001$ & $949(82.0)$ & $1817(96.0)$ & $<0.001$ \\
\hline Death (/per 100 year) & $11(0.4)$ & $10(0.2)$ & $<0.001$ & $11(0.9)$ & $10(0.5)$ & $<0.001$ \\
\hline
\end{tabular}

1pre-treatment interval, days from when a participant tested positive for HIV using a Western Blot test to when he/she initiated treatment 
Table 3 Factors associated with virological failure among all participants

\begin{tabular}{|c|c|c|c|c|c|}
\hline \multirow[b]{2}{*}{ Variable } & \multirow[b]{2}{*}{ Events/N (\%) or Median (IQR) } & \multicolumn{2}{|l|}{ Crude model } & \multicolumn{2}{|l|}{ Adjusted model } \\
\hline & & OR $(95 \%$ Cl) & $P$-value & OR $(95 \%$ Cl) & $P$-value \\
\hline \multicolumn{6}{|l|}{ Case management } \\
\hline No case management & $60 / 1549(3.9)$ & Reference & & & \\
\hline With case management & $31 / 3357(0.9)$ & $0.23(0.15-0.36)$ & $<0.001$ & $0.27(0.17-0.42)$ & $<0.001$ \\
\hline \multicolumn{6}{|l|}{ WHO Clinical stage } \\
\hline Stage | and stage || & $69 / 4368(1.6)$ & Reference & & Reference & \\
\hline Stage III and stage IV & $22 / 538(4.1)$ & $2.67(1.63-4.33)$ & $<0.001$ & $1.94(1.17-3.21)$ & 0.010 \\
\hline \multicolumn{6}{|l|}{ CD4 cell counts } \\
\hline$<500$ & $83 / 4229(2.0)$ & Reference & & Reference & \\
\hline $500+$ & $8 / 677(1.2)$ & $0.60(0.29-1.24)$ & 0.167 & $0.89(0.42-1.87)$ & 0.756 \\
\hline
\end{tabular}

case-management modality as an integral aspect to HIV care in China and could be incorporated across the country to improve patient-related outcomes and decrease the burden of disease.

In this study, the average number of days from confirmed HIV diagnosis to initiation of ART treatment was 35 days in the intervention group (those receiving casemanagement) and 56 days in the control group (those who did not receive case management). Early initiation of ART and linkage to care are necessary to achieving viral suppression, subsequently reducing the transmission of HIV and preventing new infections [19]. In China, the routine HIV screening process is convoluted, often involving multiple counseling sessions and blood draws, and due to lack of courage or lack of cognition or fear of side effects of the drugs [24], new diagnosed people are usually reluctant to come back to the clinic seeking treatment proactively. A study among older PLWH in Chongqing City, for example, found that the average time from HIV diagnosis to ART initiation was 6.3 months among those aged over 50, and almost 13 months for those between the ages of 18-49 [21]. A similar study from Yuxi, China determined an average of 447 days between HIV confirmation and treatment initiation [22]. During this pre-ART period, substantial mortality and loss to follow-up have been observed, especially among people with advanced HIV disease [11, 24, 25]. Recent randomized trials have indicated that shortening the time for patients to enter treatment can reduce this loss between diagnosis and treatment $[26,27]$, but many experts worry that shortening this "preparation time" can lead to more loss due to inadequate consultations [28]. In our study, NGO united medical staff, through establishment of communication at a personal and confidential level, HIV education and information transfer, etc. facilitates the establishment of the comprehensive case management model that resulted in fewer days between HIV diagnosis and ART initiation accompanied with better ART compliance and treatment outcome even among lower CD4 count patients. Similar findings have been reported in high-income countries, such as the United States (US). Since the AIDS epidemic began in the 1980s, the US has used case management to improve the quality of medical care, meet the needs of AIDS patients, and decrease the associated cost of care $[13,29,30]$. This has subsequently led to less unmet demand and higher rates of ART initiation in the country [31]. Thus, evidence suggests that comprehensive case management can be effective in reducing loss to follow-up and improving linkage to care, critical aspects to timely ART initiation.

Consequently, this has also led to improvements in clinical results. Specifically, in this study, the results of the multivariate logistic regression analysis indicated that patients who received the new case management model were at decreased odds of developing virological failure $(P<0.001)$, which is consistent with other findings [32-34]. More so, those receiving case management experienced consistently higher survival rates compared to those in the control group. This quicker linkage to care may have resulted in the decreased mortality in the intervention group. Mortality is also related to patient adherence, as improved ART adherence can lead to long-term viral suppression, thereby reducing morbidity

Table 4 Factors associated with the pre-treatment interval among all participants

\begin{tabular}{lllll}
\hline Variable & $\beta(95 \%(I)$ & $P$-value & $\beta(95 \%(I)$ & $P$-value \\
\hline Case management & $-30.62(-59.04,-2.20)$ & 0.035 & $-30.36(-58.78,-1.95)$ & 0.036 \\
ART Regimen & $83.26(0.69,165.82)$ & 0.048 & $82.47(-0.07,165.01)$ & 0.050 \\
\hline
\end{tabular}

ART antiretroviral treatment; $\mathrm{Cl}$ confidence interval 


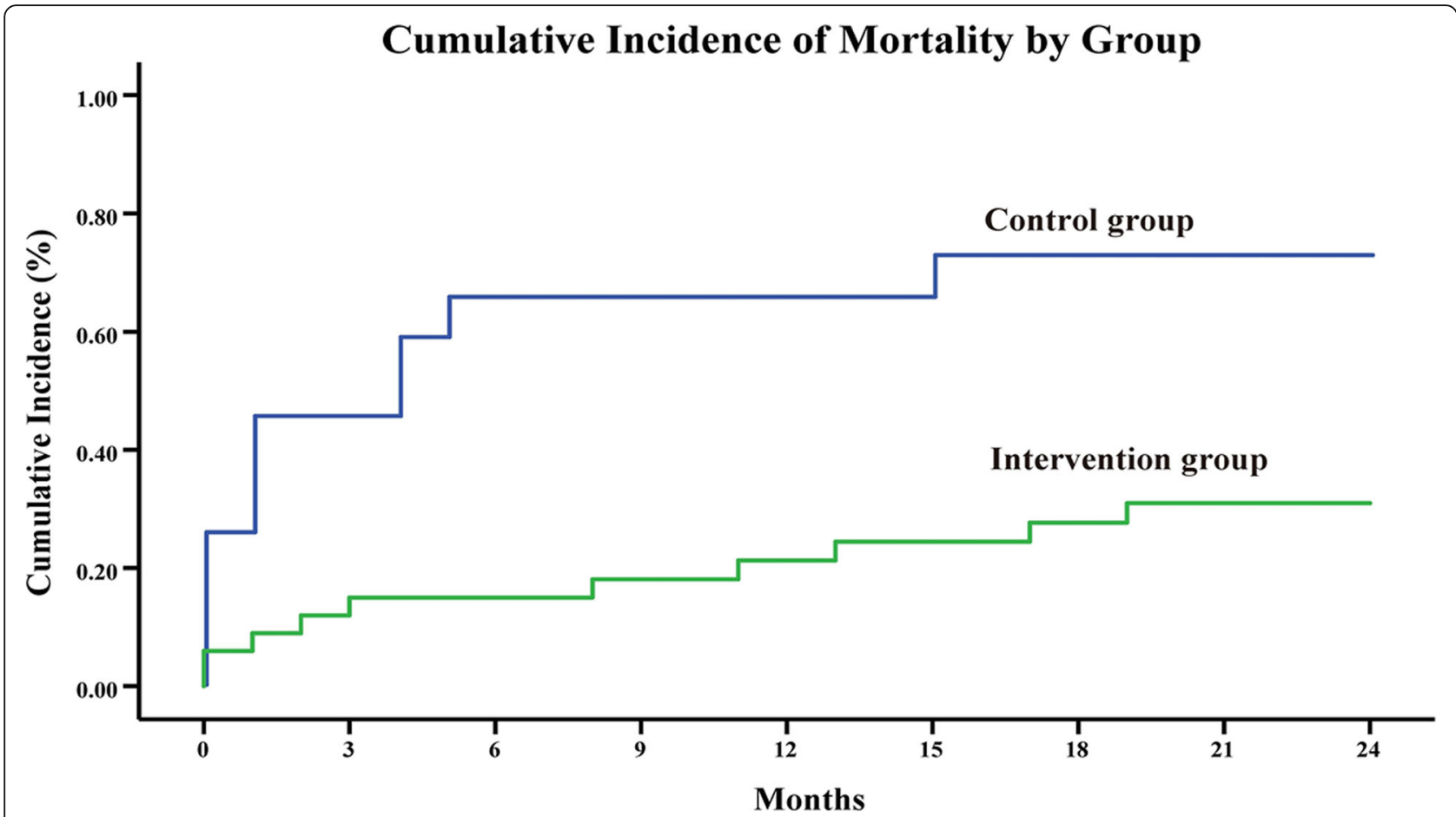

Fig. 2 Kaplan-Meier survival plot among patients with and without case management. This figure shows the cumulative incidence of mortality in the control group (blue line) and the intervention group (green line). The cumulative incidence of mortality in the control group is above the intervention group at each follow-up, indicating that the intervention group had a better survival rate throughout the study period $(P=0.023)$

and mortality [30, 34, 35]. As seen in this study and others, case management is an effective means to improving ART adherence and retention, subsequently reducing mortality. In light of this evidence, efforts to identify individuals at the beginning of their infection and streamline the process from HIV screening to ART care, such as used in this case management system, could be a beneficial tactic to include in national care guidelines. A national roll out of this multidimensional case management strategy could improve the care of PLWH in China and reduce the overall disease burden in China.

Some limitations to this study exist. As this was a retrospective study, confounding characteristics may be present. Even more, there is no way for us to conduct a periodical control, only a historical control can be set up. there were significant differences in baseline characteristics between the control and intervention groups, including age, gender, and route of transmission. But the historical control information we included was from the CRIMS information system, which was not upgraded during the entire study period. So the information of both groups can be obtained the same way, avoided the bias caused by the review of supplementary information. At the same time, multivariate analysis was used, in order to control for the influence of other imbalance factors on study results. Moving forward, a matched, casecontrol study could be implemented to further assess the impact of case management on ART initiation, adherence, and retention. Additionally, participants were restricted to those attending Beijing Youan Hospital and may not be representative of the general population living with HIV throughout China. Youan Hospital however, is one of the leading HIV care institutes in the country, where more than 9000 individuals receive care. Thus, a diverse sampling of the HIV infected population would likely be captured. Further evaluation of the case management modality in different medical departments across the country could help further supplement the findings from this study.

\section{Conclusion}

A doctor/nurse/NGO HIV case management program is feasible and could be an effective complementary strategy to improving HIV treatment outcomes in China. In order to improve patient outcomes, further understanding of the causes for loss to follow-up should be explored. Supplementing the existing case management model with real-time feedback from patients can only further strengthen this innovative intervention and improve HIV/AIDS care throughout China.

\section{Abbreviations}

NGOs: Non-governmental organizations; ART: Antiretroviral treatment; HIV: Human immunodeficiency virus; OR: Odds ratio; Cl: Confidence intervals; AIDS: Acquired immune deficiency syndrome; UNAIDS: Joint United Nations 
Program on HIV/AIDS; PLWH: People were living with HIV; WHO: World Health Organization; China CDC: Chinese Center for Disease Control and Prevention; CRIMS: HIV/AIDS comprehensive response information management system; RNA: Ribonucleic acid; IQR: Inter-quartile ranges; US: United States

\section{Acknowledgments}

We would like to thank Dr. Zunyou Wu (Chinese Center for Disease Control and Prevention) and Dr. Liyan Wang (People's Medical Publishing House) for their suggestions to the study. We apologize in advance to those researchers whose valuable work was not discussed here due to the limited focus or space of this paper.

\section{Declarations}

Nothing to declare.

\section{Authors' contributions}

Work attributed to Beijing HIV care clinic, study conception and design (LS and $\mathrm{AL}$ ). Cohort follow-up and data collection (LD, ZL, HW, TZ). Screening test for HIV infection (BS, YS, JY, TJ). Data collection and record (BS, YS, YW, $X Y)$; laboratory analysis (XY, JY, SB, XG, JW); Drafting the manuscript, data analysis and guidance on clinical guidelines (LD, SRS, XY). All authors have approved the final article.

\section{Funding}

This work was supported by the National 13th Five-Year Grand Program on Key Infectious Disease Control (Grant number:2018ZX10721102-003-003 to L.D., 2018ZX10302-102 to L.D., 2017ZX10202102-005-003 to B. S. 2017ZX10202101-004-001 to T. Z.), the National Natural Science Foundation of China (Grant number:81601795 to L. D., 81772165 to B. S.,81571973 to H.W.) The funders had no role in study design, data collection and analysis, decision to publish, or preparation of the manuscript.

\section{Availability of data and materials}

The dataset used and/or analyzed during the current study is available from the corresponding author on reasonable request.

\section{Ethics approval and consent to participate}

This study was approved by the Beijing Youan Hospital Research Ethics Committee (No. 2019-057). The participants received both written and oral information about the study before they gave their written informed consent. The participants were also assured of confidentiality.

\section{Consent for publication}

Not applicable.

\section{Competing interests}

The authors declare that they have no competing interests.

\section{Author details}

${ }^{1}$ Center for Infectious Diseases, Beijing Youan Hospital, Capital Medical University, Beijing 100069, China. ${ }^{2}$ School of Public Health, Anhui Medical University, Hefei 230032, Anhui, China. ${ }^{3}$ Lanzhou Municipality Pulmonary Hospital, Lanzhou 730046, Gan Su, China. ${ }^{4}$ The National Center for AIDS/STD Control and Prevention, Chinese Center for Disease Control and Prevention, Beijing 100037, China.

Received: 11 March 2020 Accepted: 2 July 2020

Published online: 09 July 2020

\section{References}

1. UNAIDS. Global HIV \& AIDS statistics - 2019 fact sheet; 2018

2. CCDC, NCSTD, NCAIDS. Update on the AIDS/STD epidemic in China the third quarter of 2018. Chin J AIDS STD. 2018;24:1075

3. China NHCotPsRo. Progress in AIDS prevention and treatment in China; 2018.

4. Ledergerber B, Opravil MEM, Telenti A, Hirschel B, Battegay M, et al. Clinical progression and virological failure on highly active antiretroviral therapy in HIV-1 patients: a prospective cohort study. Lancet. 1999;353:863-8.

5. Egger M, May M, Chêne G, Phillips AN, Ledergerber B, Dabis F, et al. Prognosis of HIV-1-infected patients starting highly active antiretroviral therapy: a collaborative analysis of prospective studies. Lancet. 2002;360: 119-29.

6. Sun J, Liu L, Shen J. Trends in baseline CD4 cell counts and risk factors for late antiretroviral therapy initiation among HIV-positive patients in Shanghai, a retrospctive cross-sectional study. BMC Infect Dis. 2017;17:285.

7. Panel on Antiretroviral Guidelines for Adults and Adolescents. Guidelines for the Use of Antiretroviral Agents in Adults and Adolescents with HIV. Department of Health and Human Services. Available at http://www. aidsinfo.nih.gov/ContentFiles/AdultandAdolescentGL.pdf.

8. Society EAC. Guidelines for treatment of HIV-positive adults in Europe. In.

9. Consolidated Guidelines on the Use of Antiretroviral Drugs for Treating and Preventing HIV Infection: Recommendations for a Public Health Approach. 2nd ed. Geneva: World Health Organization; 2016.

10. Saag MS, Benson CA, Gandhi RT, Hoy JF, Landovitz RJ, Mugavero MJ. Antiretroviral Drugs for Treatment and Prevention of HIV Infection in Adults: 2018 Recommendations of the international antiviral Society-USA panel. JAMA. 2018;320:379-96.

11. WHO. Guidelines for Managing Advanced HIV Disease and Rapid Initiation of Antiretroviral Therapy. Geneva: WHO; 2017.

12. HJ W. Study on the current situation and influence factors about acceptance and maintenance of ART among PLWHA: Tianjin Medical University; 2018

13. Chernesky $\mathrm{RH}$, Grube B. HIV/AIDS case management views from the frontline. Care Manag J. 1999;1:19-28.

14. Wu Z, Tang Z, Mao Y, Van Veldhuisen P, Ling W. Testing and linkage to HIV care in China: a cluster-randomised trial. Lancet HIV. 2017;4:e555-65.

15. Liu P, Tang Z, Lan G, Zhu Q, Chen H, You Y. Early antiretroviral therapy on reducing HIV transmission in China: strengths, weaknesses and next focus of the program. Sci Rep. 2018;8:3431.

16. Nwokolo N, Whitlock G, McOwan A. Not just PrEP: other reasons for London's HIV decline. Lancet HIV. 2017;4:e153.

17. Grinsztejn B, Hosseinipour MC, Ribaudo HJ, Swindells S, Eron J, Chen YQ Effects of early versus delayed initiation of antiretroviral treatment on clinical outcomes of HIV-1 infection: results from the phase 3 HPTN 052 randomised controlled trial. Lancet Infect Dis. 2014;14:281-90.

18. Labhardt ND, Ringera I, Lejone TI, Klimkait T, Muhairwe J, Amstutz A. Effect of offering same-day ART vs usual health facility referral during home-based HIV testing on linkage to care and viral suppression among adults with HIV in Lesotho: the CASCADE randomized clinical trial. JAMA. 2018;319:1103-12.

19. Mateo-Urdiales A, Johnson S, Smith R, Nachega JB, Eshun-Wilson I. Rapid initiation of antiretroviral therapy for people living with HIV. Cochrane Database Syst Rev. 2019;6:CD012962.

20. Wu Z. The progress and challenges of promoting HIV / AIDS 90-90-90 strategies in China. Chin J Dis Control Prev. 2016;20:1187-9.

21. Zürcher K, Mooser A, Anderegg N, Tymejczyk O, Couvillon MJ, Nash D, et al. Outcomes of HIV-positive patients lost to follow-up in African treatment programmes. Tropical Med Int Health. 2017;22:375-87.

22. Umeokonkwo CD, Onoka CA, Agu PA, Ossai EN, Balogun MS, Ogbonnaya LU. Retention in care and adherence to HIV and AIDS treatment in Anambra state Nigeria. BMC Infect Dis. 2019;19:654.

23. NCAIDS/STD. National handbook of free antiviral treatment for HIV/AIDS 4th ed. Beijing: People's Medical Publishing House; 2016.

24. Amanyire G, Semitala FC, Namusobya J, Katuramu R, Kampiire L, Wallenta J, et al. Effects of a multicomponent intervention to streamline initiation of antiretroviral therapy in Africa: a stepped-wedge cluster-randomised trial. Lancet HIV. 2016;3:e539-48.

25. Bastard M, O'Brien DP, Casas E, Greig J, Balkan S, Etard JF. Risk factors for mortality and lost to follow-up before antiretroviral therapy: a multicentric retrospective cohort study of 41 Médecins Sans Frontières HIV programmes. In: 8th IAS Conference on HIV Pathogenesis, Treatment, and Prevention. Vancouver Canada; 2015.

26. Rosen S, Fox MP. Retention in HIV care between testing and treatment in sub-Saharan Africa: a systematic review. PLoS Med. 2011:8:e1001056.

27. Rosen S, Maskew M, Fox MP, Nyoni C, Mongwenyana C, Malete G. Initiating antiretroviral therapy for HIV at a patient's first clinic visit: the RaplT randomized controlled trial. PLoS Med. 2016;13:e1002050.

28. Helova A, Akama E, Bukusi EA, Musoke P, Nalwa WZ, Odeny TA. Health facility challenges to the provision of option B1 in western Kenya: a qualitative study. Health Policy Plan. 2017;32:283-91.

29. Grube B, Chernesky RH. HIV/AIDS case management tasks and activities. Soc Work Health Care. 2001;32:41-63. 
30. Marseille EA, Kevany S, Ahmed I, Feleke G, Graham B, Heller T, Kahn JG, Reyes M. Case management to improve adherence for HIV-infected patients receiving antiretroviral therapy in Ethiopia: a micro-costing study. Cost Eff Resour Alloc. 2011:9:18.

31. Katz MH, Cunningham WE, Fleishman JA, Andersen RM, Kellogg T, Bozzette $S A$, et al. Effect of case management on unmet needs and utilization of medical care and medications among HIV-infected personsn. Ann Intern Med. 2001;135:557-65.

32. Shaboltas AV, Skochilov RV, Brown LB, Elharrar VN, Kozlov AP, Hoffman IF. The feasibility of an intensive case management program for injection drug users on antiretroviral therapy in St. Petersburg, Russia. Harm Reduct J. 2013; 10:15

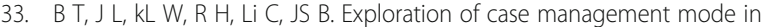
antiretroviral therapy. J Dermatol Venereol. 2018:40:171-3.

34. HX C. Effect of case management on treatment adherence among AIDS patients. Jiangsu J Prev Med. 2019;30:163-7.

35. Amico KR, Harman JJ. Efficacy of antiretroviral therapy adherence interventions : a research synthesis of trials, 1996 to 2004. J Acquir Immune Defic Syndr. 2006;41:285-97.

\section{Publisher's Note}

Springer Nature remains neutral with regard to jurisdictional claims in published maps and institutional affiliations.

Ready to submit your research? Choose BMC and benefit from:

- fast, convenient online submission

- thorough peer review by experienced researchers in your field

- rapid publication on acceptance

- support for research data, including large and complex data types

- gold Open Access which fosters wider collaboration and increased citations

- maximum visibility for your research: over $100 \mathrm{M}$ website views per year

At BMC, research is always in progress.

Learn more biomedcentral.com/submissions 